\title{
Low-cost densification of permanent GPS networks for natural hazard mitigation: First tests on GSI's GEONET network
}

\author{
Chris Rizos ${ }^{1}$, Shaowei Han ${ }^{1}$, Linlin $\mathrm{Ge}^{1}$, Horng-Yue Chen $^{1}$, Yuki Hatanaka ${ }^{2}$, and Kaoru Abe ${ }^{2}$ \\ ${ }^{1}$ School of Geomatic Engineering, University of New South Wales, Sydney, NSW 2052, Australia \\ ${ }^{2}$ Geographical Survey Institute, Ministry of Construction, Kitasato-1, Tsukuba, Ibaraki 305, Japan
}

(Received January 16, 2000; Revised May 31, 2000; Accepted June 2, 2000)

\begin{abstract}
Researchers from The University of New South Wales (UNSW), Australia, and from the Geographical Survey Institute (GSI), Japan, have commenced a joint project to develop, deploy and test an innovative hardware/software system design for an automatic, continuously-operated ground deformation monitoring system based on low-cost GPS receiver technology. Conventional continuously-operated GPS (CGPS) networks, such as the one established in Japan by GSI to precisely measure earth surface movement, are very expensive. The high cost being primarily due to the fact that dual-frequency receivers are used. Japan's nationwide GEONET network is the world's largest, numbering nearly 1000 receiver stations, with an average station spacing of the order of $30 \mathrm{~km}$. In order to densify such CGPS networks (important when high spatial resolution for the monitoring of the deformation phenomenon is required), and to promote the use of the CGPS technique in lesser developed countries, a significantly cheaper system architecture is needed. The proposed design is an integrated, dual-mode network consisting of low-cost, single-frequency GPS receivers across the area of interest, surrounded by a sparser network of dual-frequency GPS receivers. Initial tests of data collected at selected stations in the GEONET network have already shown that through enhanced data processing algorithms a CGPS network containing both single-frequency and dual-frequency receivers would be able to deliver better than centimetre level accuracies, at considerably lower cost than present systems based exclusively on dual-frequency instrumentation. This paper reports the results of the first field test of this new CGPS system design, in the Tsukuba area of Japan, in August 1999. The test network consisted of: (a) several stations of the GEONET network surrounding (b) an inner network of four single-frequency Canadian Marconi GPS receivers installed by UNSW researchers. The data from both the GEONET and the UNSW receivers were processed using a specially modified version of the Bernese GPS Software Package. The software first processes the GEONET GPS station data in order to generate empirical corrections which are then applied to the double-differenced data of the GPS baselines located within the test area enclosed by the dual-frequency CGPS stations. These corrections have the effect of improving baseline solution accuracy by up to an order of magnitude, even for baselines ranging up to $100 \mathrm{~km}$ in length. The baselines connecting the inner network to the surrounding GEONET stations are processed in a number of modes, including $24 \mathrm{hr}$ files (as is the standard practice for geodynamic applications) and hourly data files (as in volcano deformation monitoring applications). The results indicate that single-frequency-withcorrection processing can achieve accuracies of better than $5 \mathrm{~mm}$ in the horizontal components and $3 \mathrm{~cm}$ in height, while the dual-frequency results can achieve accuracies better than $2 \mathrm{~mm}$ in the horizontal components and $6 \mathrm{~mm}$ in height. In the authors' opinion, for certain geodynamic applications there are no significant differences between the single-frequency-with-correction results and the dual-frequency results, especially for the horizontal components.
\end{abstract}

\section{Introduction}

Permanently operating GPS networks have been used for many years in support of geodetic applications. Data from these networks are usually collected on a daily basis, centrally archived at data centres, and are available via the Internet to users. Many of these users, through the application of special carrier phase processing techniques, are able to achieve relative station coordinate accuracies as high as a "few parts per billion" (sub-centimetre accuracy for receiver separations up to a thousand kilometres or more). However, typically "sub-parts per million" accuracies (sub-ppm: 0.1 ppm implies an accuracy of $1 \mathrm{~cm}$ in $100 \mathrm{~km}$ baseline) are considered to be indicative of "GPS Geodesy" techniques.

Copy right(C) The Society of Geomagnetism and Earth, Planetary and Space Sciences (SGEPSS); The Seismological Society of Japan; The Volcanological Society of Japan; The Geodetic Society of Japan; The Japanese Society for Planetary Sciences.
The range of applications that can be addressed using GPS Geodesy techniques is growing rapidly.

Though the spatial resolution of the GEONET is now as high as about $30 \mathrm{~km}$, due to the high cost of dual-frequency GPS receivers they may not be established in a dense enough configuration to address all of the geodetic applications. One of them, the monitoring of pre-seismic or post-seismic faulting, requires sub-km resolution as indicated by the faulting length in Table 1. One option for increasing the geodetic network's spatial resolution is to use low-cost receivers (e.g. single-frequency receivers, which are priced at most at one tenth of dual-frequency receivers) to densify the dualfrequency network (in a so-called "hard" densification mode). The dual- and single-frequency stations are treated as reference and user stations respectively. Another option is to integrate CGPS with techniques such as differential 
Table 1. Earthquake surface faulting (compiled from various sources).

\begin{tabular}{|c|c|c|c|c|c|}
\hline \multirow[t]{2}{*}{ Locality } & \multirow[t]{2}{*}{$\begin{array}{c}\text { Date } \\
(\mathrm{dd} / \mathrm{mm} / \mathrm{yy})\end{array}$} & \multirow[t]{2}{*}{$\begin{array}{l}\text { Magnitude } \\
\text { (M) }\end{array}$} & \multirow[t]{2}{*}{$\begin{array}{l}\text { Length } \\
(\mathrm{km})\end{array}$} & \multicolumn{2}{|c|}{$\begin{array}{c}\text { Maximum } \\
\text { displacement (m) }\end{array}$} \\
\hline & & & & Horizontal & Vertical \\
\hline Chedrang Fault, India & $12 / 06 / 1897$ & 8.7 & 19 & & 11.0 \\
\hline Formosa & $16 / 03 / 1906$ & 7.1 & 48 & 2.5 & 1.3 \\
\hline California, USA & $18 / 04 / 1906$ & 8.3 & 434 & 6.4 & 1.0 \\
\hline Nevada, USA & 03/10/1915 & 7.8 & 32 & & 4.5 \\
\hline Murchison, New Zealand & $16 / 06 / 1929$ & 7.6 & 4 & & 4.6 \\
\hline Chile & $22 / 05 / 1960$ & 8.3 & 1600 & & \\
\hline Alaska, USA & 28/03/1964 & 8.5 & 900 & 6.0 & 6.0 \\
\hline Iran & $31 / 08 / 1968$ & 7.4 & 27 & 4.0 & \\
\hline
\end{tabular}

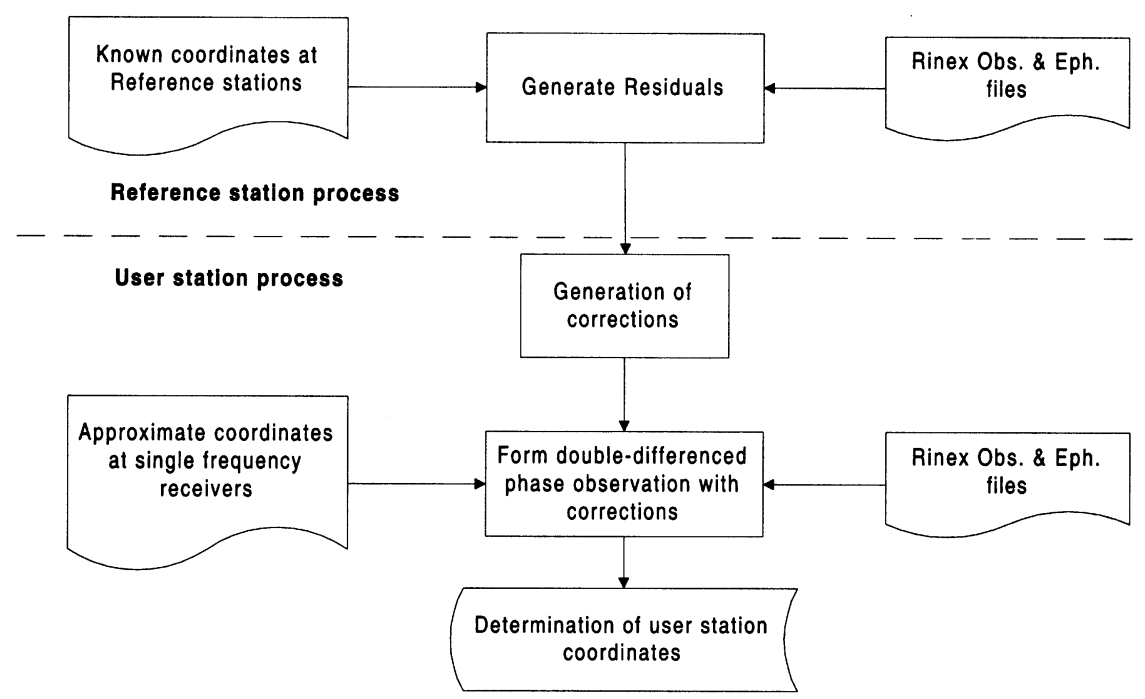

Fig. 1. Flow chart of data processing procedure.

Synthetic Aperture Radar Interferometry (InSAR) (so-called "soft" densification, since no additional GPS hardware installation is needed, see Ge et al., 1999). As described in several previous studies (e.g. Rizos et al., 1998; Chen et al., 1999), the "hard" densification data processing strategies have been developed in order to ensure sub-ppm relative accuracy even for baselines up to $100 \mathrm{~km}$ in length.

In this paper, the data processing algorithm is first briefly described. The UNSW-GSI experimental results are then discussed.

\section{Data Processing Algorithm}

The double-differenced observable can be written as:

$$
\begin{aligned}
\nabla \Delta \phi= & \nabla \Delta \rho+\nabla \Delta d \rho+\lambda \cdot \nabla \Delta N-\nabla \Delta d_{i o n} \\
& +\nabla \Delta d_{\text {trop }}+\nabla \Delta d_{m p}^{\varphi}+\varepsilon_{\nabla \Delta \phi}
\end{aligned}
$$

where $\Delta \nabla$ represents the double-differencing operator; $\phi$ : the carrier phase observation in units of metres: $\rho:=\left(X^{s}-\right.$ $X), X^{s}$ is the satellite position vector, $X$ is the station position vector; $d \rho$ : the effect of ephemeris errors (including S/A ef- fects, if any); $\lambda$ : the wavelength of the carrier; $N$ : the integer ambiguity for a particular satellite-receiver pair; $d_{\text {ion }}, d_{\text {trop }}$, $d_{m p}^{\phi}$ and $\varepsilon_{\nabla \Delta \phi}$ are the ionospheric delay, tropospheric delay, multipath effect and the carrier phase observation noise for a particular one-way observation, respectively (Han, 1997).

From Han (1997), Eq. (1), through a linear combination (assume the number of GPS reference stations is three), can be written as:

$$
\begin{aligned}
\nabla \Delta \phi_{u, 3}-\left[\alpha_{1} \cdot V_{1,3}+\alpha_{2} \cdot V_{2,3}\right]= & \nabla \Delta \rho_{u, 3}+\lambda \cdot \nabla \Delta N_{u, 3} \\
& +\varepsilon \sum_{i=1}^{3} \alpha_{i} \cdot \nabla \Delta \phi_{i} \cdot
\end{aligned}
$$

The subscripts refer to the receiver stations: $1,2,3$ are the reference stations, and $u$ is the user station(s). It is assumed here that reference station 3 is the "primary" one, used to generate double-differences with the various user stations (u). The parameters $\alpha_{i}$ can be determined, based on the conditions given in Han and Rizos (1996) and Wu (1994):

$$
\sum_{i=1}^{3} \alpha_{i}=1
$$


and

$$
\sum_{i=1}^{3} \alpha_{i} \cdot\left(\vec{X}^{s}-\vec{X}_{i}\right)=0
$$

The residual vectors are formed from the double-differenced observations between reference stations 1 and 3 , and 2 and 3 :

$$
\begin{aligned}
& V_{1,3}=\nabla \Delta \phi_{1,3}-\nabla \Delta N_{1,3}-\nabla \Delta \rho_{1,3} \\
& V_{2,3}=\nabla \Delta \phi_{2,3}-\nabla \Delta N_{2,3}-\nabla \Delta \rho_{2,3}
\end{aligned}
$$

By comparing Eqs. (1) and (2), it can be seen that the orbit bias, ionospheric delay, tropospheric delay and multipath bias have been eliminated or significantly reduced. This means that once the reference station data have been used to estimate the ambiguities and coordinates, the residual vectors can be created using Eq. (5). Then every user receiver station can receive the correction term $\left[\alpha_{1} \cdot V_{1,3}+\alpha_{2} \cdot V_{2,3}\right]$ (reference station number 3 is assigned as an original point) and use Eq. (2) to aid in the determination of the double-differenced ambiguities.

From the algorithm discussed above, the data processing procedure will involve 2 steps. The first step is to derive the residuals from the 3 or more reference stations using Eq. (5). Based on the approximate position of any single-frequency receiver, the linear combination coefficients can be derived and the correction term (the second term on the left-hand side of Eq. (2)) can be generated. The second step is to apply this correction term to the double-differenced carrier phase observations between the one primary reference receiver and a single-frequency receiver. The standard rapid static positioning procedure can then be used to resolve integer ambiguities and derive the ambiguity-fix solution for the coordinates. This correction term can also be applied to two single-frequency receivers for determining the baseline between these receivers. This procedure is depicted in Fig. 1,

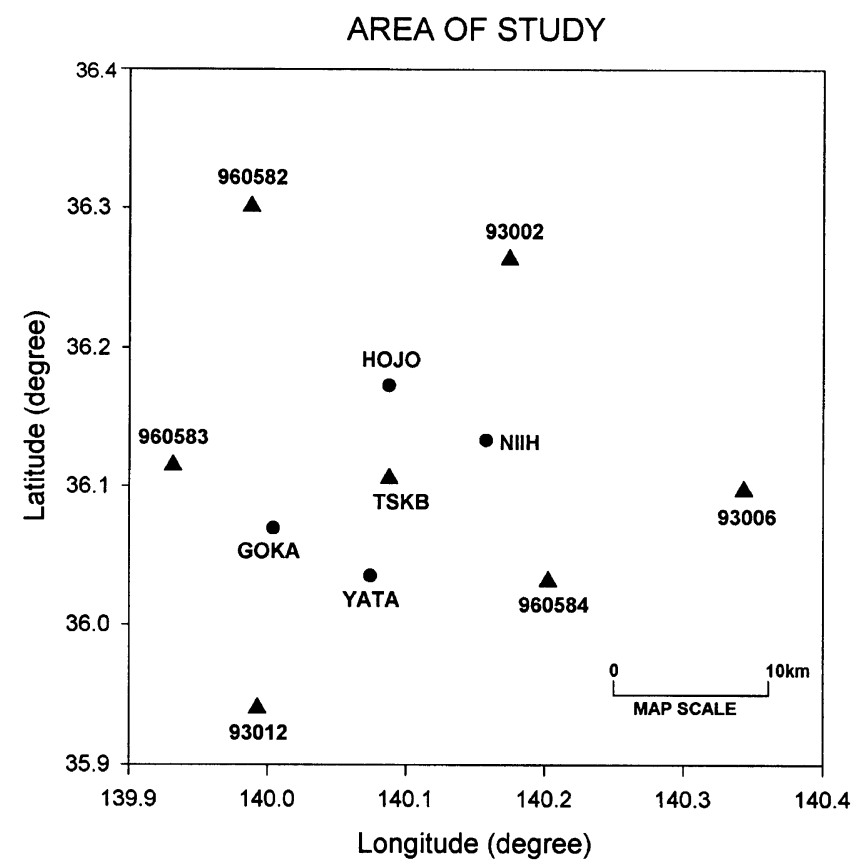

Fig. 2. The UNSW-GSI test network around Tsukuba, Japan. and has been implemented within the Bernese GPS software package.

\section{The UNSW-GSI Experiment}

In August 1999, an experiment was carried out within the GEONET around Tsukuba, Japan (Fig. 2), to field test low-cost, single-frequency GPS receivers (Canadian Marconi Company (CMC) receivers) side-by-side with geodetictype GPS receivers (Trimble 4000SSE). The objectives were to test the UNSW method of integrated data processing, to analyse the coordinate results obtained by this procedure compared with standard multi-station processing using the

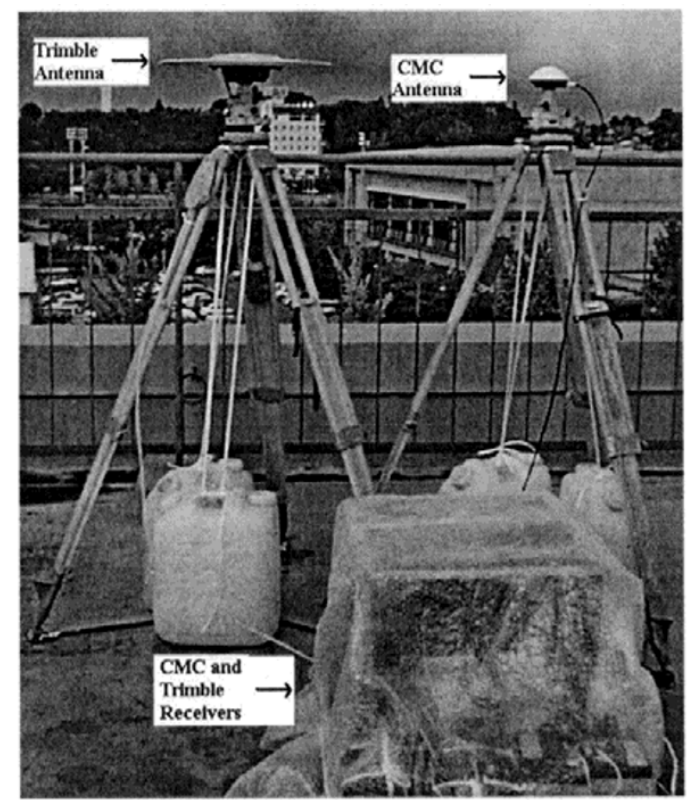

Fig. 3. Configuration at antenna swapping site.

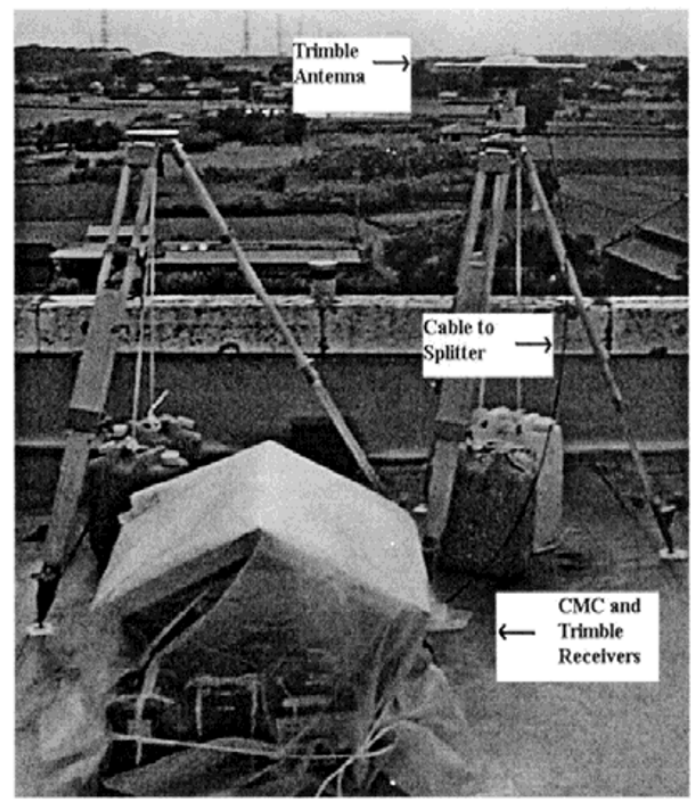

Fig. 4. Configuration at antenna sharing site. 
Table 2. Comparison of single-frequency (with correction) and dual-frequency long-session results (mean and std. devs.).

\begin{tabular}{|c|c|c|c|c|c|c|c|}
\hline Stations & Frequency & Obs. & $\begin{array}{l}\text { Latitude } \\
\text { (mm) }\end{array}$ & $\begin{array}{l}\text { Longitude } \\
\quad(\mathrm{mm})\end{array}$ & $\begin{array}{l}\text { Height } \\
(\mathrm{mm})\end{array}$ & $\begin{array}{l}\text { Length } \\
\text { (mm) }\end{array}$ & $\begin{array}{c}\text { Distance } \\
(\mathrm{km})\end{array}$ \\
\hline \multirow[t]{2}{*}{ YATA } & Dual & 1 & -3.0 & 3.0 & -1.4 & -0.7 & 12.9 \\
\hline & Single & 5 & $1.6 \pm 5.5$ & $-3.2 \pm 2.5$ & $-11.0 \pm 5.2$ & $-0.5 \pm 5.8$ & \\
\hline \multirow[t]{2}{*}{ YATT } & Dual & 4 & $1.2 \pm 0.7$ & $-1.0 \pm 1.7$ & $0.9 \pm 3.2$ & $0.4 \pm 1.5$ & 12.9 \\
\hline & Single & 2 & $1.9 \pm 0.2$ & $0.1 \pm 4.7$ & $-13.4 \pm 4.5$ & $1.6 \pm 2.8$ & \\
\hline \multirow[t]{2}{*}{ GOKA } & Dual & Nil & & & & & 14.4 \\
\hline & Single & 5 & $-0.8 \pm 1.8$ & $0.0 \pm 2.7$ & $-24.3 \pm 4.7$ & $-0.8 \pm 1.6$ & \\
\hline \multirow[t]{2}{*}{ GOKT } & Dual & 4 & $0.6 \pm 2.5$ & $-0.5 \pm 1.6$ & $0.4 \pm 6.4$ & $0.5 \pm 2.4$ & 14.4 \\
\hline & Single & 2 & $3.6 \pm 0.2$ & $2.1 \pm 2.2$ & $-9.6 \pm 1.9$ & $3.6 \pm 0.4$ & \\
\hline \multirow[t]{2}{*}{$\mathrm{NIIH}$} & Dual & 1 & -2.3 & 1.1 & -7.0 & -1.3 & 26.1 \\
\hline & Single & 2 & $-3.3 \pm 7.9$ & $-2.3 \pm 1.6$ & $20.7 \pm 4.5$ & $-4.0 \pm 7.4$ & \\
\hline \multirow[t]{2}{*}{ NIIT } & Dual & 4 & $1.5 \pm 1.2$ & $-0.5 \pm 1.1$ & $2.1 \pm 10.1$ & $1.1 \pm 1.6$ & 26.1 \\
\hline & Single & 1 & -1.6 & 1.3 & 13.5 & -0.4 & \\
\hline \multirow[t]{2}{*}{ HOJO } & Dual & Nil & & & & & 27.2 \\
\hline & Single & 4 & $-5.1 \pm 1.8$ & $-6.9 \pm 0.8$ & $-1.4 \pm 8.3$ & $-7.0 \pm 1.8$ & \\
\hline \multirow[t]{2}{*}{ HOJT } & Dual & 4 & $0.6 \pm 0.9$ & $-0.4 \pm 0.9$ & $0.0 \pm 6.5$ & $0.4 \pm 1.0$ & 27.2 \\
\hline & Single & 1 & -5.4 & -4.9 & -4.0 & -6.7 & \\
\hline
\end{tabular}

Bernese Software, and to establish a test network for future UNSW-GSI tests. Four temporary sites, equipped with both CMC and Trimble receivers, with antennas atop two closely spaced tripods, were set up as user stations in the Goka, Hojo, Niihari, and Yatabe districts of Tsukuba. The tripods initially occupied by the CMC antennas are denoted as GOKA, HOJO, NIIH, and YATA. The tripods initially occupied by Trimble antennas are denoted as GOKT, HOJT, NIIT, and YATT. GEONET stations 93002, 93006, 93012, 960582, 960583, and 960584 were used as reference stations in the experiment.

The experiment consisted of two phases. In phase 1 both the UNSW single-frequency receivers and the GSI dualfrequency receivers were operating continuously, side-byside, for two days. In phase 2 the four test sites were divided into two groups, with two sites in each group. An antenna swapping test was carried out in the first group (Niihari and Yatabe) (Fig. 3), while antenna sharing was implemented in the second group (Goka and Hojo) (Fig. 4). Data were collected for 8 hours each day over a three day period.

\section{Results and Discussion}

The "true" coordinate values for the four temporary sites were computed using data from the whole campaign (from DoY 214 to 224 1999). The GEONET station 93012 coordinate was held fixed, and in all the following analysis the true values have been removed from the latitude, longitude, height and length components. The comparisons have been made for both the long-session and the hourlysession tests. ('Long-session' refers to 24 and 8 hour data sets for phases 1 and 2, respectively.) In the hourly-session processing there were 387 and 475 data files, for the dualfrequency and single-frequency receivers respectively. (The single-frequency receivers logged data during the weekend, 7-8 August, hence there are more single-frequency files than dual-frequency ones.)

Table 2 shows the mean values and standard deviations of the long-session results for the different stations. Some stations were only occupied once, therefore no standard deviations are shown. Comparing the mean value and standard deviation derived from the analysis of dual-frequency data with those derived from the single-frequency data with corrections (as determined using Eq. (5) results), the horizontal components (latitude, longitude and length) are not significantly different. In the case of the height component the variations of the single-frequency-with-correction results are larger, especially at station GOKA. In general, singlefrequency-with-correction processing can achieve accuracies better than $5 \mathrm{~mm}$ in the horizontal components, and $3 \mathrm{~cm}$ in height, while dual-frequency processing can achieve better than $2 \mathrm{~mm}$ in the horizontal components and $6 \mathrm{~mm}$ in height. The column labelled "Distance" is the approximate distance from station 93012 to the user stations.

Table 3 gives the ambiguity resolution success rate and the standard deviations of relative positioning. The QIF (Quasi Ionosphere-Free) method is used to fix the integer ambiguity on the hourly dual-frequency data, while the search method is used to process the single-frequency data (Rizos et al., 1998). The variations of the dual-frequency and single-frequencywith-correction results are similar for all the components. Because the biases (e.g. ionospheric delay, tropospheric delay and orbit error) are effectively reduced, the ambiguity 
Table 3. Comparison of single-frequency (with corrections) and dual-frequency hourly-session results (mean and std. devs.).

\begin{tabular}{cccccc}
\hline Frequency & $\begin{array}{c}\text { Ambiguity } \\
\text { success rate }\end{array}$ & $\begin{array}{c}\text { Latitude } \\
(\mathrm{mm})\end{array}$ & $\begin{array}{c}\text { Longitude } \\
(\mathrm{mm})\end{array}$ & $\begin{array}{c}\text { Height } \\
(\mathrm{mm})\end{array}$ & $\begin{array}{c}\text { Length } \\
(\mathrm{mm})\end{array}$ \\
\hline Dual & $91 \%$ & $0.6 \pm 5.5$ & $0.0 \pm 6.4$ & $-3.2 \pm 22.9$ & $0.5 \pm 5.3$ \\
& $(352 / 387)$ & & & & \\
Single & $99 \%$ & $0.2 \pm 5.9$ & $-2.3 \pm 5.9$ & $-9.9 \pm 18.0$ & $-0.8 \pm 5.8$ \\
& $(471 / 475)$ & & & & \\
\hline
\end{tabular}

Table 4. The antenna sharing results (mean and std. devs.).

\begin{tabular}{ccccc}
\hline Frequency & $\begin{array}{c}\text { Latitude } \\
(\mathrm{mm})\end{array}$ & $\begin{array}{c}\text { Longitude } \\
(\mathrm{mm})\end{array}$ & \multicolumn{1}{c}{$\begin{array}{c}\text { Height } \\
(\mathrm{mm})\end{array}$} & \multicolumn{1}{c}{$\begin{array}{c}\text { Length } \\
(\mathrm{mm})\end{array}$} \\
\hline Dual & $1.9 \pm 2.2$ & $-0.6 \pm 1.7$ & $3.1 \pm 4.9$ & $1.7 \pm 2.1$ \\
Single & $2.9 \pm 1.1$ & $0.3 \pm 3.4$ & $-11.9 \pm 4.2$ & $2.3 \pm 2.3$ \\
\hline
\end{tabular}

resolution success rates are higher in the case of the singlefrequency-with-correction results.

In order to compare the single-frequency and the dualfrequency receiver in terms of relative positioning ability, splitters were used in phase 2 of the experiment so that the two receivers shared the same Trimble antenna. According to the results in Table 4, the height component from the singlefrequency-with-corrections processing is $9 \mathrm{~mm}$ worse than that from the dual-frequency processing, while the latitude, longitude and length results are virtually the same.

\section{Concluding Remarks}

The following comments can be made:

1. The long-session ( 24 and $8 \mathrm{hr}$ sessions) results indicate that single-frequency-with-correction processing can achieve accuracies of better than $5 \mathrm{~mm}$ in the horizontal components and $3 \mathrm{~cm}$ in height, while the dual-frequency results can achieve accuracies better than $2 \mathrm{~mm}$ in the horizontal components and $6 \mathrm{~mm}$ in height.

2. It has been shown in the antenna sharing experiment that the single-frequency and dual-frequency results have similar quality (especially for the horizontal components).

3. Hourly-session results indicate that the ambiguity resolution success rate of dual-frequency processing is less than that of single-frequency-with-correction processing. When ambiguities are resolved, there are no significant differences between the results.
Acknowledgments. This study is supported by grants from the Australian Research Council (ARC) under the IREX (International Researcher Exchange) Scheme and the Large Grant Scheme. Several GSI personnel are gratefully acknowledged for their help in the experiment.

\section{References}

Chen, H. Y., C. Rizos, and S. Han, Rapid static medium-range GPS positioning techniques for geodynamic applications, 4th International Symp. on Satellite Navigation Technology and Applications, Brisbane, Australia, 20-23 July, paper 49, 12 pp., 1999.

Ge, L., S. Han, and C. Rizos, Interpolation of GPS results incorporating geophysical and InSAR information, Pres. International Symposium on GPS-Application to Earth Sciences and Interaction with Other Space Geodetic Techniques, Tsukuba, Japan, 18-22 October, 1999.

Han, S., Carrier phase-based long-range GPS kinematic positioning, Ph.D. Dissertation, UNISURV S-49, School of Geomatic Engineering, The University of New South Wales, Sydney, Australia, 185 pp., 1997.

Han, S. and C. Rizos, GPS network design and error mitigation for realtime continuous array monitoring systems, 9th Int. Tech. Meeting of the Satellite Division of the U.S. Inst. of Navigation GPS ION '96, Kansas City, Missouri, 17-20 September, 1827-1836, 1996.

Rizos, C., S. Han, and H.-Y. Chen, Carrier phase-based, medium-range, GPS rapid static positioning in support of geodetic applications: algorithms and experimental results, Spatial Information Science and Technology Symp., Wuhan, P.R. China, 13-16 December, 7-16, 1998.

Wu, J. T., Weighted differential GPS method for reducing ephemeris error, Manuscripta Geodaetica, 20, 1-7, 1994.

C. Rizos (e-mail: c.rizos@unsw.edu.au), S. Han, L. Ge, H.-Y. Chen, Y. Hatanaka, and K. Abe 